\title{
SEQUÊNCIA DE ENSINO INVESTIGATIVA NO ENSINO DE CIÊNCIAS: UMA PESQUISA COM UMA CLASSE DE IDOSOS DO PMEA - PROGRAMA MUNICIPAL DE EDUCAÇÃO DE ADULTOS, NÍVEIS 1, 2 E 3*
}

Débora Rocha Sandra Gonçalves Vilas Bôas

\section{Introdução}

Neste capítulo apresentamos referencial teórico, metodologia e uma sequência de ensino investigativa, de uma pesquisa de mestrado desenvolvida junto ao programa de mestrado profissional em educação: formação docente para educação básica, UNIUBE/Campus Uberlândia.

Iniciamos nossas reflexões, falando um pouco sobre o espaço escolar, a questão de pesquisa e os participantes. Trazemos considerações sobre o ensino de Ciências na EJA e apresentamos o desenvolvimento da Atividade Prática - "Condução de água nas plantas", a partir da qual mostramos os contributos da Sequência de ensino investigativa para ensinar e aprender Ciências a um grupo de Idosos com idade acima de 65 anos.

A Lei de Diretrizes e Bases da Educação Nacional (LDBEN) busca efetivar uma educação de qualidade, beneficiando intervenções e atividades, que complementam o ensino e a construção do conhecimento, a utilização de métodos práticos e diversificados, estimulando a compreensão e o processo de novas descobertas.

Levando em consideração as concepções que envolvem a Educação de Jovens e Adultos (EJA), é muito importante buscar metodologias que contribuam para aulas investigativas, dinâmicas e desafiadoras, que possibilitem o desenvolvimento de atividades que incentivem a busca de conhecimentos e a permanência dos adultos e idosos no ambiente escolar.

Para que, no espaço escolar, haja real interesse pelo conteúdo apresentado, e para que os alunos se sintam confortáveis, participativos, livres para exporem o que pensam e sanarem suas dúvidas, bem como

${ }^{*}$ DOI - 10.29388/978-65-86678-84-0-0-f.233-252 
possam demonstrar suas habilidades e competências, tendo seus conhecimentos prévios respeitados, faz-se necessário que os docentes estejam envolvidos em todo o processo de ensinar e aprender. Assim, durante o trabalho de pesquisa, procuramos olhar para o ensino de Ciências, respeitando esses pressupostos e adequando as atividades propostas à realidade e às possibilidades de cada turma.

De acordo com essa concepção, buscamos compreender nesta pesquisa: Como as Atividades Práticas podem contribuir para a construção de conceitos no ensino de Ciências no Programa Municipal de Educação de Adultos (PMEA), Níveis 1, 2 e 3? Para nos ajudar nessa compreensão, utilizamos como método de investigação as "Atividades Práticas", norteadas pela Sequência de Ensino Investigativa (Carvalho, 2018), buscando efetivar, através do diálogo e da aplicação dessas sequências os conhecimentos acerca dos conteúdos de Ciências, apresentados no conteúdo curricular do PMEA.

A fim de alcançar os propósitos estabelecidos na pesquisa, foi definido como objetivo geral investigar e compreender de que forma as Atividades Práticas podem contribuir para os estudantes do PMEA, e como os conceitos alusivos ao ensino de Ciências, nos níveis 1, 2 e 3 podem ser compreendidos.

Para alcançar esse objetivo geral, foi necessário estabelecer alguns objetivos específicos que delinearam a pesquisa, como: Diagnosticar, por meio de diálogo com a professora, os conteúdos do ensino de Ciências, que são trabalhados nas salas de aula do PMEA, nos níveis 1, 2 e 3; Analisar os documentos curriculares que fundamentam o ensino do PMEA; Articular conhecimentos prévios, teoria e prática estruturadas junto aos estudantes; Elaborar e desenvolver as atividades práticas de acordo com os conteúdos curriculares do PMEA; Observar e compreender como os estudantes interagem no desenvolvimento das atividades práticas.

A pesquisa foi realizada em uma sala de aula do PMEA, com as seguintes turmas: no Nível 1 , com alunos de primeiro e de segundo ano; no nível 2, alunos de segundo e de terceiro ano; no nível 3, alunos de quinto ano. Essa sala de aula está instalada no Centro Educacional de Assistência Integrada (CEAI), na cidade de Uberlândia - MG. Esses centros oferecem, no Ensino Básico, assistência na área da saúde e assistência social; promovem, ainda, ações que integram a cultura, o lazer e o bem-estar desses idosos, a fim de que eles descubram e desenvolvam suas habilidades e aptidões; 
esses centros proporcionam, ainda, a convivência com o meio social e familiar.

O público atendido nos CEAl's está na faixa etária igual ou superior a 60 (sessenta) anos, ou seja, na terceira idade. Dessa forma, os participantes da pesquisa compõem um grupo de idosos, sujeitos de suas próprias histórias, tendo em comum o fato de não terem passado pelo processo de alfabetização na idade mais apropriada. Assim, participaram da pesquisa 24 alunos, todos com idade igual ou superior aos 60 (sessenta) anos, sendo 22 (vinte e duas) mulheres e 02 (dois) homens.

A produção de dados foi realizada na própria sala, no decorrer das aulas, tanto durante como ao final de cada atividade e aconteceram em dois momentos, em que desempenhamos um duplo papel: o de observadora-participante e o de mediadora das "Atividades Práticas". Para melhor compreender a pergunta da pesquisa, utilizamos diferentes instrumentos, como: registros fotográficos e de vídeos, notas de campo e rodas de conversa.

No primeiro momento, foram levantados pontos para relembrar o conteúdo apresentado na aula teórica e para verificar os conhecimentos prévios que os alunos têm em relação às abordagens teóricas que norteiam o trabalho; nesse momento eram apresentados, aos participantes da pesquisa, os objetivos da Atividade Prática. Vale destacar que o intuito maior da pesquisa não é, somente, a obtenção dos resultados, mas, principalmente, as contribuições que estes resultados possibilitarão para os participantes no processo de ensino e aprendizagem.

No segundo momento, após a aplicação das atividades, foram realizadas rodas de conversa, com o propósito de investigar se as Atividades Práticas contribuíram para a obtenção dos conteúdos e para a efetivação dos conhecimentos, sendo importante destacar que essas ações foram realizadas em todas as atividades propostas.

Nesta pesquisa, optamos em trabalhar com a roda de conversa, por ser uma metodologia que permite a cooperação entre os sujeitos e proporciona uma troca de informações entre eles, incentivando a interação, a partir da qual são trabalhadas as relações de convivência.

$\mathrm{Na}$ próxima seção, explicitaremos nosso referencial teórico, apresentando nossa concepção para o ensino de ciências na EJA e o papel das atividades práticas na Educação de Jovens, adultos e idosos, bem como delimitaremos a fundamentação teórica que norteia as atividades práticas, ou seja, a Sequência de Ensino Investigativa (SEI). 


\section{O Ensino de Ciências na EJA, Sequências de Ensino Investigativa (SEI) e "Atividades Práticas"}

Com a expansão da tecnologia, o ensino de Ciências passou a ser primordial para a economia do país. Nesse sentido, foram feitos investimentos para a melhoria do ensino de Ciências, culminando com a efetivação da Constituição Federal brasileira, no ano de 1988, que buscava atender os movimentos educacionais progressistas, na tentativa de garantir a todos o acesso à educação e ao conhecimento. Esse direito de acesso à educação de base para todos, estendeu-se aos jovens e adultos.

Dessa forma, a Lei da Educação Nacional e as Diretrizes Curriculares para a EJA estabelece finalidades e objetivos da educação para o funcionamento das práticas pedagógicas, e ao se referirem ao aluno da EJA, os autores explicam:

[...] é importante levar em conta que o aluno se encontra inserido no mundo do trabalho e das relações interpessoais, trazendo consigo uma história mais longa (e provavelmente mais complexa) de experiências, conhecimentos acumulados e reflexões sobre o mundo externo, sobre si mesmo e sobre as outras pessoas, necessitando a escola valorizá-la, se possível dentro do conteúdo das disciplinas, de forma transversal como também sugerem os PCN'S. (SANTOS et al., 2005, p. 415).

Entendemos que a escola deve valorizar o saber do aluno da EJA, sua experiência e conhecimentos adquiridos na sociedade em que está inserido, bem como associar a sua realidade ao conteúdo da disciplina de Ciências Naturais e Cidadania.

Nesse sentido, o ensino de Ciências, na modalidade EJA permite alcançar o que Krasilchik (2008, p. 37) afirma ser, um aspecto essencial, que "é dar voz aos sujeitos e aos seus saberes, à medida que os currículos, livros e professores precisam partir de ideias comumente trazidas pelos estudantes à escola". Isso é possível na medida em que a disciplina de Ciências permite a utilização de diferentes metodologias, de forma que a curiosidade dos alunos seja estimulada. A partir disso, pode-se despertar o interesse do aluno pelo conteúdo desenvolvido e, consequentemente, a participação efetiva nas atividades teóricas e práticas. 
Como afirmam Bezerra e Santos (2016), a história de vida e os conhecimentos prévios dos alunos da EJA são necessários, pois, além do conhecimento popular deve-se alcançar o conhecimento científico. Para que possa acontecer essa ressignificação tem-se a contribuição das aulas práticas, já que, é assim, que se permite aos educandos abordarem objetivamente o seu mundo, bem como se sintam preparados para encontrarem soluções para problemas complexos com os quais se depararão na sociedade em que estão inseridos (LUNETTA, 1991). Ademais, nessa prática propõe-se ao professor, questionar os alunos quanto à sua realidade associando-a aos conhecimentos construídos no espaço escolar.

Assim, as propostas realizadas em sala de aula, a partir de reflexões e discussões, devem buscar o desenvolvimento de uma visão crítica, no que se refere à disciplina de Ciências voltada para o respeito de seu próprio corpo, de suas relações com o meio em que vivem e, ainda, com as transformações que acontecem nos diversos campos de sua vida (SILVA et al., 2004).

\section{As Sequências de Ensino Investigativo (SEI) e as "Atividades práticas"}

As Sequências de Ensino Investigativo (SEI) possuem etapas que se constituem em uma sequência de atividades planejadas, compatíveis com os referenciais teóricos, criando um ambiente investigativo para que os alunos possam se desenvolver, gradativamente, e para que ampliem sua cultura científica. Carvalho (2018, p. 9) propõe "criar um ambiente investigativo em sala de aula de Ciências, de tal forma que se possa ensinar (conduzir/ mediar) os alunos no processo (simplificado) do trabalho científico para que possam gradativamente ir ampliando sua cultura científica". Desse modo, os alunos vão adquirindo, nessas aulas investigativas, a linguagem científica. É partindo desse contexto que a autora propõe a Sequência de Ensino Investigativo (SEI).

Nessa perspectiva, as Sequências de Ensino Investigativo (SEI) buscam o diálogo e a participação efetiva dos envolvidos, do conhecimento teórico para o planejamento e as interações didáticas. Nessa dinâmica, pode-se conhecer o entendimento dos alunos, comparando o que fizeram e o que pensaram ao resolver o problema proposto na SEI. 
Segundo Carvalho (2018), as principais etapas que compõem a SEI, de acordo com o planejamento e as interações didáticas são: levantamento dos conhecimentos prévios dos alunos; o problema; resolução do problema e levantamento de hipóteses; sistematização coletiva do conhecimento; contextualização social do conhecimento e avaliação.

a) Conhecimentos prévios dos alunos: esta parte inicial da SEI é fundamental para a realização e sequência das atividades, pois os alunos terão oportunidade de exporem seus conhecimentos e experiências adquiridos, até então, em seu cotidiano. Esse é um momento que lhes dá condições para interação com seus pares, para relacionarem com o tema proposto pela professora, mostrarem a construção de seus conceitos, o que Ihes possibilitam discutir, questionar, ouvir e argumentar sobre suas ideias formadas, para que possam adquirir novos conhecimentos.

b) Problema: esta etapa é considerada como um desafio tanto para os alunos, como, especialmente, para os professores dos primeiros anos do Ensino Fundamental, pois ao realizarem experiências que oferecem algum perigo, como por exemplo o uso do fogo. Nesse caso, a experiência exige que a manipulação seja feita pelo professor, tornando, assim, uma demonstração investigativa. Vale ressaltar que o problema, também, pode ser proposto a partir de uma figura de jornal, de ideias expostas pela Internet, com textos já do domínio dos alunos, denominados de problemas não experimentais.

c) Levantamento de Hipóteses para Resolução do Problema: baseado nos conhecimentos e manipulação do material escolhido, os alunos vão levantar hipóteses e testá-las para resolverem o problema. 0 gerenciamento da classe, o planejamento das interações didáticas entre alunos e colegas e entre professores e alunos são tão importantes como o planejamento do material didático e a elaboração do problema (SPERANDIO et al., 2017). Segundo Sperandio et al. (2017), essas ações do professor e dos alunos são dispostas em etapas. A atividade prática proposta "Condução de água nas plantas" conta com a etapa de distribuição do material experimental e proposição do problema pelo professor: o professor divide a turma, distribui ou apresenta o material, propõe o problema ou vai indagando aos alunos sobre seus conhecimentos prévios, que trazidos do cotidiano, possam levá-los até o problema. Nessa etapa, a professora deve promover a indagação para que todos possam compreender qual seja o problema, sem dar a solução, nem mostrar como manipular o material para não impedir o aluno de pensar. 
d) Resolução do Problema: a etapa de resolução do problema, pelos alunos, é a mais importante das ações manipulativas, pois permite-lhes levantarem suas hipóteses e testarem-nas, pois ao serem analisadas, se derem certo, terão a oportunidade de construir conhecimento, e se não derem certo, tornam-se importantes para sua reconstrução, pois é a partir do erro que os alunos terão confiança em afirmarem sobre o que entendem como sendo certo e eliminam as variáveis que não interferem na resolução do problema. A resolução do problema deve ser realizada em pequenos grupos, onde alunos com desenvolvimento intelectual semelhante têm mais facilidade de comunicação; o que envolve, também, a parte afetiva, pois sentem mais facilidade de exporem suas ideias aos colegas do que ao professor.

e) Sistematização Coletiva dos Conhecimentos elaborados nos grupos, essa etapa é quando o professor verifica se os grupos terminaram de resolver o problema; recolhe o material experimental; desfaz os pequenos grupos e organiza um grande grupo em círculo proporcionandoIhes uma visão ampla. Nesse momento, alunos e professor preparam-se para o debate. Assim, o aluno deve ter um tempo para sistematização coletiva do conhecimento, para relembrar o que fez, colaborando na construção do conhecimento que está sendo sistematizado. O papel do professor, agora, é o de indagar sobre a resolução do problema, o que aconteceu, como aconteceu, o que eles conseguiram extrair com a resolução do problema. Todos esses questionamentos possibilitarão aos alunos tomarem consciência sobre suas próprias ações, percebendo em que momento passaram da ação manipulativa para a ação intelectual, apresentando, também, as hipóteses que deram certo, como foram testadas. Tudo isso, leva-os ao início do desenvolvimento de atitudes científicas como levantamento de dados e a construção de evidências. A partir de outros questionamentos, a professora levará os alunos a buscarem justificativas para o fenômeno, apresentando uma argumentação científica, possibilitando a ampliação do vocabulário dos alunos. No Ensino Fundamental e Médio, a sistematização dos dados leva à construção de atividades, tornando indispensável a mediação do professor para conduzir o aluno à construção do conceito.

f) Contextualização Social do Conhecimento, tem-se, aqui, a etapa do escrever e desenhar. É necessário um período para a aprendizagem individual, assim os alunos devem escrever e desenhar sobre o que aprenderam na aula; oportuniza-se, assim, como atividades complementares, o diá- 
logo e a escrita, atividades fundamentais nas aulas de Ciências, pois essas práticas apresentam-se como instrumentos de aprendizagem que realçam a construção pessoal do conhecimento (OLIVEIRA; CARVALHO, 2005).

g) A Avaliação ocorre durante toda a aplicação das atividades e sua realização, durante a aula teórica, exposição dos conhecimentos prévios, das atividades práticas, dos registros anotados, da interação dos alunos com seus pares, durante as rodas de conversas e entrevistas; e, ainda, se necessário no momento da avaliação formativa.

Entende-se, dessa maneira, que aplicando as etapas e adequando as ações, pode-se utilizar procedimentos e instrumentos de coleta de dados que possibilitarão identificar o conhecimento prévio dos alunos. As Sequências de Ensino Investigativo (SEI), segundo Carvalho (2018), são aulas que o professor/mediador planeja com sequências de atividades. Desse modo, oferece aos alunos condições para apresentarem seus conhecimentos prévios e iniciarem novos saberes, construindo ideias próprias, tornando-se capazes de discuti-las com os colegas e com o professor, e, assim, saltando do conhecimento cotidiano para o conhecimento científico, adquirindo condições de entenderem conhecimentos já estruturados por gerações anteriores.

As Sequências de Ensino Investigativo tipificam um ensino por investigação que, segundo Carvalho (2018), apresentou-se como estratégia de trabalhos que promovem, no ensino de Ciências, a aprendizagem por investigação como práticas inovadoras de trabalhos. Nesses termos, percebe-se um cenário mundial acompanhando esse progresso, a educação voltada para novas tendências que viabilizam uma aprendizagem dinâmica e interativa.

As Atividades Práticas oportunizam o desenvolvimento de diversas habilidades nos sujeitos participantes, como, por exemplo, a de investigação e diálogo com os conceitos teóricos, que possibilita ao aluno discutir as questões que foram identificadas antes, durante e ao final da realização das atividades. Esse movimento possibilita aos alunos confrontarem e discutirem as ideias e as hipóteses que foram observadas e levantadas interativamente durante a atividade, assim como permite aos alunos que vivenciem os experimentos realizados.

As atividades das SEls foram preparadas visando alcançar os interesses e os objetivos propostos no ensino de Ciências na matriz curricular do PMEA, tendo o cuidado de dialogar com a professora sobre a coerência dessas atividades para a compreensão dos alunos. 
As "Atividades Práticas" foram planejadas segundo a proposta de Sequências de Ensino Investigativo (SEI), apresentada por Carvalho (2018), ou seja: identificação dos conhecimentos prévios; proposição do problema e levantamento das hipóteses; resolução do problema; as etapas seguintes que aconteceram durante a roda de conversa, são: sistematização coletiva do conhecimento e sistematização individual do conhecimento.

Para identificação dos conteúdos prévios, iniciamos cada "Atividade Prática" indagando sobre o conteúdo, para que os alunos pudessem interrelacionar com o tema; fizemos perguntas que possibilitaram discussões sobre os conceitos e ideias que pudessem contribuir para as etapas seguintes. Na sequência, propusemos a realização das "Atividades práticas" que foram trabalhadas, de acordo com os temas abordados. Para os momentos de demonstrar a experimentação, foram distribuídos materiais para que os alunos, em grupos ou duplas, desenvolvessem-nas com base nas orientações.

$\mathrm{Na}$ etapa de Proposição do problema e levantamento das hipóteses, foi o momento em que explanamos o conteúdo, questionamos os alunos, provocamos situações sobre o tema que fizessem surgir soluções e novas indagações.

Na terceira etapa, momento da Resolução do Problema, os alunos participaram das aulas práticas em sala de aula para a melhor aprendizagem dos conceitos e/ou conteúdo de Ciências.

Sistematização coletiva do conhecimento, foi a quarta etapa, momento pós-atividade prática. Nesse momento, foi proposta uma roda de conversa, entre todos os envolvidos: professora, alunos e pesquisadora, para que discutissem sobre o que compreenderam da atividade. A roda de conversa não teve começo nem fim, assim todos os participantes tiveram direito à palavra. Foram levantados pontos para que os alunos pudessem explicar o que aprenderam com a atividade, se ela conseguiu contribuir para o processo de aprendizagem, de que maneira ela ajudou, o que pôde ser observado na atividade prática e o que pôde ser compreendido com os conceitos.

Para a Sistematização individual do conhecimento foi proposto aos alunos responderem um questionário, construído com perguntas que direcionam o objetivo das Atividades Práticas, para analisarmos se realmente as atividades conseguiram alcançar os propósitos idealizados.

A fase de contextualização social do conhecimento aconteceu simultaneamente com a fase de sistematização coletiva do conhecimento. 
A pesquisadora girou a roda de conversa, de forma a extrair o que os alunos alcançaram com a atividade e as suas percepções de inserção dos conceitos no cotidiano. Foi o momento também de coletar sugestões sobre o que deveria ser modificado ou melhorado e sobre o que deu e o que não deu certo na Atividade Prática.

A Avaliação, embora esteja colocada como última etapa, ocorreu durante todo o processo, desde a realização da aula teórica, da exposição do problema, das atividades práticas e dos registros, em que os alunos puderam dialogar coletiva e individualmente, por meio das rodas de conversas. No entanto, ao final, se necessário, pode ser feita uma avaliação formativa para investigar qual a contribuição das Atividades Práticas na busca de conceitos para o ensino de Ciências.

É importante destacar que durante a realização das Atividades Práticas, estabelecemos diálogo com os alunos acerca das suas experiências e o que estavam compreendendo naquele instante, bem como, suas percepções da aplicação do conteúdo no cotidiano. As Atividades Práticas foram sempre resolvidas no coletivo.

Desenvolvemos 05 atividades práticas: A Pirâmide alimentar: relações entre o conhecimento científico e a prática alimentar saudável; Identificação de amido nos carboidratos, por meio do lodo (I parte) e Identificação de vitamina C nos alimentos e sucos, por meio do lodo (II Parte); Ciclo da água; Condução da Água nas plantas e As Fases da Lua.

O objeto de conhecimento escolhido para a 1a "Atividade Prática" foi nutrição, tema que está relacionado aos conteúdos de Bioquímica Celular, que são eles: Carboidratos, Lipídeos, Proteínas e Vitaminas; como continuidade deste conteúdo, desenvolvemos a segunda e a terceira etapas da "Atividade Prática", foi a identificação de amido e vitamina C. Na 3a "Atividade Prática" trabalhamos com a água e suas propriedades, seus estados e seu ciclo, voltados para o objeto de conhecimento ambiental, ainda abordando este tema, aplicamos a 4a Atividade Prática sobre o Reino Plantae, a classificação dos organismos e a passagem de água e nutrientes nas plantas. Finalizando, trabalhamos na $5 \underline{a}$ "Atividade Prática" os satélites naturais e artificiais da terra, por meio de uma atividade que demonstrou as fases da lua.

Na próxima seção, apresentamos a descrição da 4ạ "Atividade prática", a partir da qual tecemos nossas reflexões sobre as contribuições dessa metodologia para o ensino de Ciências no PMEA, sob os fundamentos de nossas categorias de análise, levando em consideração as etapas da SEI. 


\section{Atividade Prática: “Condução de água nas plantas"}

Com duração de três horas, utilizando rosas brancas, anilina azul e vermelha, água, copos descartáveis, tesoura e estilete, realizamos esta atividade com o objetivo de demonstrar a condução da água nas plantas.

Seguindo as orientações da SEI para identificação dos conteúdos prévios, iniciamos a aula, demonstrando os materiais que seriam utilizados na realização desta "Atividade Prática". As rosas naturais brancas foram passadas de mesa em mesa para que os participantes pudessem visualizar e rememorar os saberes e experiências do cotidiano, quanto ao assunto.

Em seguida, realizamos os seguintes procedimentos: - Colocamos cinco copos com água, acrescentamos as anilinas azul e vermelha nos copos e fizemos diferentes cortes no caule das rosas. Para proporcionar uma interação inicial dos alunos com os materiais e o conteúdo a ser trabalhado, começamos passando as rosas de mesa em mesa, e logo em seguida iniciamos a abordagem teórica dialogada. Para iniciar a investigação, fizemos alguns questionamentos: $O$ que vocês acham que vamos fazer com esse material?

Sujeito I: A flor vai ficar colorida. Sujeito J: Vai colorir a flor.

Sujeito A: Ela vai ficar pigmentada.

Pesquisadora: Vai colorir de que maneira? Mas por que vocês acham que colore?

Sujeito I: com a anilina; porque ela vai sugar a água.

Sujeito M: vai sugar a anilina através da água.

Vocês sabem o porquê elas sugam a água e a anilina? Por que eu estou usando as rosas de cor branca?

Sujeito I: Porque o caule delas é poroso.

Sujeito J: Quando a gente planta a plantinha o caule faz com que ela receba tudo que está no solo, da mesma maneira, são essas rosas, elas vão receber tudo que está na água do copo que está representando o solo.

Sujeito J: Uma cor mais forte de rosa a coloração não ia destacar. Sujeito C: Não ia mostrar a coloração se fosse em uma rosa escura.

À medida que fomos organizando os materiais para a realização da "Atividade Prática", passamos para as etapas de proposição do problema e 
levantamento de hipóteses, onde fizemos questionamentos com o intuito de contribuir para a abordagem teórica do assunto e identificar os conhecimentos que os alunos já possuíam.

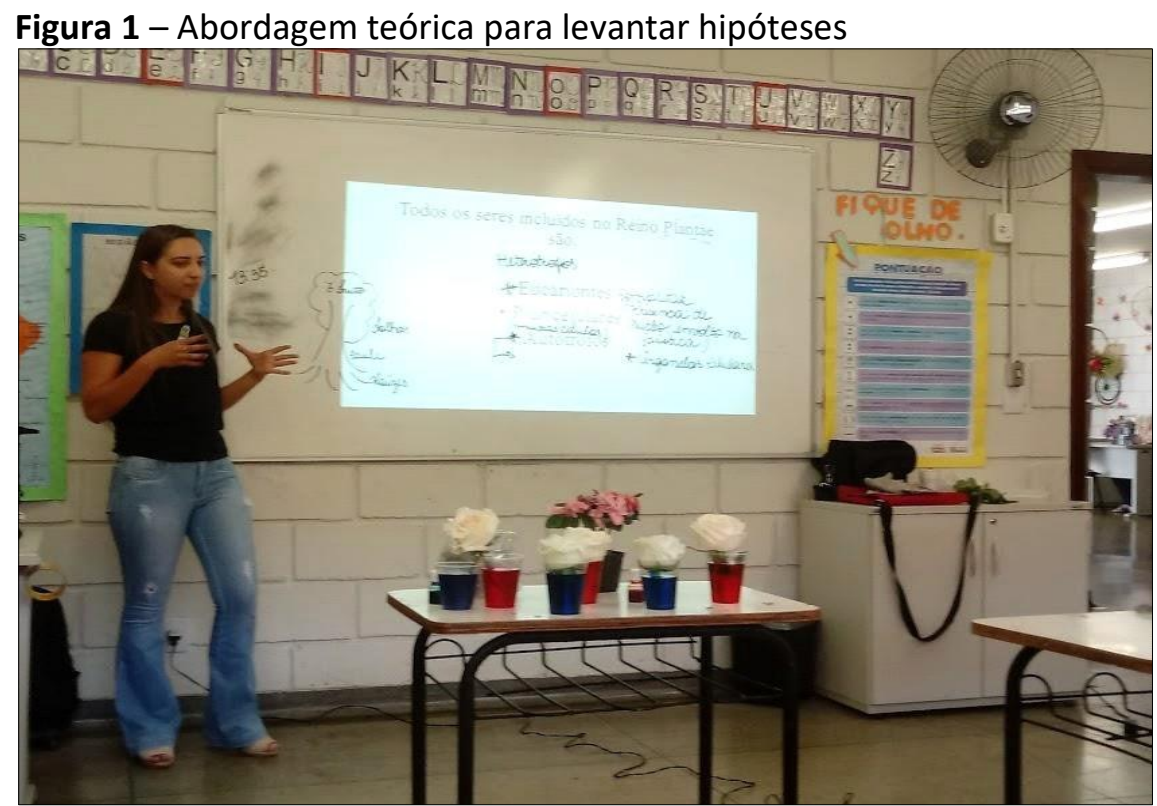

Fonte: Rocha, 2019, p.85

Iniciamos investigando os conhecimentos que os alunos trazem do cotidiano a respeito do assunto: - Sobre as plantas, vocês acham que elas são seres vivos? Por que vocês acham que as plantas são seres vivos?

Sujeito A: Claro que são seres vivos, pois são obras de Deus. Sujeito J: Porque elas "nasce, cresce e morre". Sujeito M: Se você não aguar ela, não zelar dela ela morre, tem que colocar adubo, dar água. Sujeito C: Umas gostam de chuva, outras gostam mais de calor.

Dando continuação na segunda etapa da SEI, ao explanar o conteúdo, fomos questionando e provocando os alunos, criando situações sobre o tema para que buscassem soluções e, assim, novas indagações foram surgindo. Qual será a cor que as flores vão ficar, um pouco vermelha, um pouco azul, como será que elas vão ficar? Se misturarmos a anilina azul 
com a anilina vermelha que cor ficaria? À medida que questionávamos, abordávamos, também, os conhecimentos teóricos.

Sujeito A: Uai ela vai ficar mesclada; ou lilás ou marrom. Sujeito B: Tinta bisnaga; vai ficar roxo. Sujeito I: Marrom; Mesclado de um lado azul e dou outro vermelho. Sujeito J: Metade vai ficar com o lado azul e metade vai ficar com o lado vermelho.

E quanto ao tempo da transformação, vocês acham que demora quanto tempo para acontecer a transformação?

Sujeito B: Umas duas horas. Sujeito A: Uma hora e meia. Sujeito I: Depende de como a planta vai reagir, então eu acho que para ela reagir vai demorar uns 30 minutos. Sujeito A: Uma hora e meia. Sujeito C: Uma hora e quarenta minutos.

Para complementar a fala dos alunos e contribuir na abordagem teórica, explicamos que as plantas são seres vivos porque elas nascem, crescem e se reproduzem, soltam excretas, transpiram, se alimentam e fazem trocas gasosas. Continuamos com os levantamentos de hipóteses: Vocês sabem o que significa a expressão "trocas gasosas"?

Sujeito A: são gases. Sujeito J: As plantas também trocam de roupa, porque as folhas caem e surgem novas folhas. Sujeito B: As Plantas têm esse oxigênio, porque elas têm amor, já viu aquelas pessoas com depressão forte que são rodeadas de flor, porque perto das plantas elas encontram amor e paz.

Vocês sabem dizer o que é oxigênio, o que vocês entendem com essa palavra?

Sujeito J: É a respiração. Sujeito A: oxigênio é o cérebro da planta, nós não temos o nosso cérebro? então é como se o oxigênio fosse o cérebro da planta.

Onde fica o oxigênio nas plantas? Sujeito J: Nas folhas. Sujeito A: No caule. Sujeito B: Pé de arvore chora sabia! Sujeito I: Se você chegar perto de um pé de árvore e dizer que vai cortar os galhos dele eles choram pingam água, principalmente o pé de mangueira. 

das árvores?

O que serão essas gotas que aparecem, quando cortam os galhos

Sujeito I: são lágrimas, elas choram. Sujeito I: Débora, lá em casa tem árvores, tem uma dama da noite e algumas árvores, quando demora chover que vai para chover, no outro dia amanhece tudo respingado, não choveu mais amanheceu tudo respingado.

Prosseguimos: Ah, não choveu! Então, o que você acha que aconteceu com a sua plantinha?

Sujeito I: Eu acho que ela está chorando pedindo água.

Pesquisadora: Será mesmo que é choro? Sujeito I: Eu acho que ela está chorando pedindo água.

Pesquisadora: Assim como nós, porque nós transpiramos por meio do suor. E as plantas será que elas transpiram também? Sujeito J: Sim, elas transpiram.

Pesquisadora: De que maneira vocês acham que elas transpiram? A gente pode ver a transpiração dessas plantas? Sujeito I: Ver a gente não pode, mas pode sentir elas um pouco mais molhada, de vez em quando.

A cada diálogo descrito acima e nos demais, e para dar sequência ao pensamento dos alunos, fomos mediando o conhecimento cotidiano deles com o conhecimento científico, sempre com intervenções onde procurávamos utilizar expressões que fossem de fácil compreensão para os alunos

Vocês sabem dizer por que as plantas precisam do sol para a sua própria sobrevivência?

Sujeito A: Sem o sol a planta não vive, eu plantei um pezinho de pimenta no sol e ele ficou a coisa mais bonita, depois eu fui e plantei um pezinho de limão na sombra e ele não sobreviveu, porque não tinha sol.

Intervenção da Pesquisadora: A água quando está passando para as outras partes da planta e chega às folhas, ela não vai voltar para trás, porque elas chegam às folhas e entram em contato com o sol e, aí, por meio do contato com o sol os estômatos dessas folhas se abrem, porque a folha é como se fosse a pele, ela tem uma epiderme, ela tem células e essas 
células são cheias de estômatos, durante o dia esses estômatos se abrem para a passagem de água, então a planta passa água e entra luz por dentro desses estômatos..

Sujeito I: E elas têm, também, parece uma veinha (diminutivo de veia). O que será aquelas veinhas (diminutivo de veias).

Pesquisadora: Aquelas veinhas (diminutivo de veias), são nervuras e a água passa por essas veinhas também, essas nervuras fazem parte das células da planta, a folha é composta por várias células, então nas nervuras também passam água como se fossem as nossas veias passando sangue.

Sujeito J: E as plantas que não vai ao sol?

Pesquisadora: As plantas que não vão ao sol não precisam de água? Algumas plantas elas não ficam em contato com o sol, mas precisam de um pouco de luz, porque elas se alimentam por meio da luz, a não ser que elas sejam uma planta parasita que se alimentam da seiva bruta de outra planta, nas quais existem exceções que são poucas, mas existem.

Após esses diálogos, iniciamos a etapa de "Resolução do problema". Como já havíamos colocado a "Atividade Prática" em ação, ou seja, colocar as rosas brancas dentro dos copos com água e anilina, ao longo da abordagem teórica dialogada, fomos chamando a atenção dos alunos para que percebessem alguns sinais de transformação que as rosas já vinham apresentando.

Prosseguindo a aula, chegamos à etapa de "Sistematização coletiva do conhecimento". Essa etapa aconteceu com uma roda de conversa entre todos os envolvidos, isto é, professoras, alunos e pesquisadora para conversarem com o que compreenderam da atividade. As perguntas geradoras foram propostas para realizar uma síntese dos conhecimentos populares/cotidiano com os conhecimentos científicos na direção dos fatores que contribuem para a sobrevivência e condução de água e nutrientes nas plantas.

Pesquisadora: Vocês acham que é possivel ver a transpiração que ocorre nas plantas? Sujeito I: Agora depois de toda explicação eu acho que é possivel visualizar sim essa transpiração. Quando a gente pega nas plantas que elas estão molhadinhas, isso pode ser um exemplo de transpiração. 
Pesquisadora: Vocês acham que a transpiração das plantas, elas interferem no desenvolvimento das plantas? Sujeito J: Sim, ela a ajuda a crescer de uma maneira saudável, pois se a planta não fizer transpiração ela morre.

Pesquisadora: Agora vamos lá! Vamos ver se vocês conseguiram compreender sobre as plantas? O que são estômatos? Sujeito J: São alguns buraquinhos que estão na folha da planta e se abrem quando recebem a luz do sol e para a passagem de água, esses buraquinhos são iguais os da nossa pele que sai suor.

Intervenção da Pesquisadora: Assim sendo, vale ressaltar que os estômatos só abrem durante o dia, ou seja, aquela plantinha que não fica exposta ao sol, ela não vai conseguir sobreviver. Quando o sol está muito quente as plantas acabam ressecando, porque, às vezes, elas não recebem água na mesma medida em que elas estão perdendo para o meio ambiente, porque quando tem muito sol, enquanto tem luminosidade os estômatos estão abertos para a passagem de água e para receber a luminosidade, então quando está muito quente a plantinha sofre um pouquinho, pois os estômatos ficam abertos o tempo todo e a plantinha perde muita água.

$\mathrm{Na}$ etapa final das SEls tem-se a "Avaliação" em que o aluno pode ser avaliado pela sua participação e interesse durante a aula, sendo observado, também, o seu comportamento em grupo, formulação de perguntas e hipóteses coerentes, interesse e cuidado na montagem da "Atividade Prática". O roteiro de acompanhamento do experimento, com registro da montagem, hipóteses iniciais e respostas das perguntas elaboradas pela professora. Integrando-se à pesquisa, a professora sugeriu que os alunos investigassem temas associados ao conteúdo aplicado e trabalhado.

\section{Análise dos dados:}

É sobretudo, na análise do cenário das "Atividades Práticas" que nos propomos responder à questão central de nossa pesquisa: Como as Atividades Práticas podem contribuir para a construção de conceitos no ensino de Ciências no Programa PMEA - Programa Municipal de Educação de Adultos, Níveis 1, 2 e 3 ?

Optamos pelo processo de triangulação que permite comparar, criticar e averiguar a coerência das informações que estão sendo 
apresentadas. De acordo com Minayo (2010), a triangulação, pode ser usada para realizar uma análise mais profunda, em diversos trabalhos. A autora ainda ressalta sobre triangulação que é uma "combinação e cruzamento de múltiplos pontos de vista" (MINAYO, 2010, p. 29).

Nesse caso, a triangulação foi utilizada, nesta pesquisa, para compreender diferentes aspectos que fundamentam o estudo. Nesse sentido, a construção dos resultados ocorreu a partir da produção dos dados, cruzando as observações durante a realização das atividades práticas, os registros realizados e os diálogos estabelecidos nas Rodas de conversa.

Concluiu-se que a aula foi significativa, alcançando os objetivos propostos, ou seja, compreender o processo de condução de água nas plantas, a hipótese levantada inicialmente, que a rosa ficaria colorida foi confirmada, a turma participou com interesse e sentiram-se à vontade para questionar e apontar seus conhecimentos populares e científicos, formalizados durante a realização da "Atividade prática". Por fim, o conteúdo desta aula levou os alunos a observarem todas as etapas do processo de condução de água nas plantas, questionando, argumentando e participando ativamente de toda a experiência vivenciada. A "Atividade Prática" possibilitou aos alunos notarem, nitidamente, o caminho que a água percorreu para chegar até as pétalas e a importância da água; descobriram que isso acontece porque o caule da flor absorve a água, irrigando toda a planta até atingir as pétalas. Perceberam que a água estava carregada de pigmentos coloridos, esses pigmentos percorrem pequenos vasos até ficarem depositados nas pétalas, deixando-as coloridas. As pétalas ficaram coloridas, pois a água que foi conduzida do caule para as pétalas, estava com anilina, isso ilustra que todos os nutrientes que estão contidos na água percorrem desde a raiz até as pétalas das rosas.

A partir dessas observações, foi possível: identificar a forma como os alunos apresentam suas percepções de inserção dos conceitos no cotidiano; oportunizou coletar sugestões sobre o que deveria ser modificado ou melhorado e sobre o que não deu certo na atividade prática e perceber que o saber popular dos alunos relativo às plantas está se transformado em saber científico.

Essa percepção é possível quando observamos durante a atividade os alunos acrescentarem em seus relatos novas palavras que foram acrescidas em seu vocabulário, entre elas pode destacar nas respostas: saber popular $=$ vai chupar a anilina através da água, para saber científico $=$ 
Vai sugar a anilina através da água; saber popular = conservar o meio ambiente, para saber científico = preservar o meio ambiente; saber popular = as plantas choram quando são cortadas, para saber científico = quando cortam os galhos interrompe o processo de condução e é derramado a água que já havia sido conduzida no caule; saber popular = Sem o sol a planta não vive, eu plantei um pezinho de pimenta no sol e ele ficou a coisa mais bonita, depois eu fui e plantei um pezinho de limão na sombra e ele não sobreviveu, porque não tinha sol, para saber científico = A água quando está passando para as outras partes da planta e chega às folhas, ela não volta, porque elas chegam às folhas e entram em contato com o sol e, por meio desse contato, os estômatos dessas folhas se abrem, elas têm células e essas células são cheias de estômatos, durante o dia esses estômatos se abrem para a passagem de água, e entra luz por dentro desses estômatos; saber popular = As folhas têm, (...) parece uma veinha (diminutivo de veia), para saber científico = são nervuras e a água passa por essas veinhas também, essas nervuras fazem parte das células da planta, a folha é composta por várias células, nas nervuras também passam água como se fossem as nossas veias passando sangue.

Por fim, a realização dessa "Atividade Prática", levando em consideração a mediação entre os saberes populares e científicos, possibilitou a construção dos seguintes conceitos: estruturas das plantas (raízes, caule, folhas, fruto, estômatos e a clorofila); respiração e transpiração; processo de fotossíntese e de condução de água.

\section{Considerações finais:}

Retomando o problema da pesquisa buscou-se compreender: Como as Atividades Práticas podem contribuir para a construção de conceitos no ensino de Ciências no Programa PMEA - Programa Municipal de Educação de Adultos, Níveis 1, 2 e 3? Para ajudar nessa compreensão, associou-se os conhecimentos prévios e as vivências dos alunos com os fundamentos científicos, por meio de atividades práticas que foram utilizadas como método de investigação e resolução de problema, utilizando materiais simples, buscando efetivar, através do diálogo e da aplicação das "Atividades práticas", os conhecimentos acerca dos conteúdos de Ciências apresentados no conteúdo curricular do PMEA.

Ao aplicar a Sequência de Ensino Investigativa e propor aos alunos o levantamento de hipóteses para solucionar o problema apresentado, ao 
sistematizar os conhecimentos, os alunos trabalharam com variáveis relevantes, do fenômeno científico.

As ideias sobre os conceitos trabalhados na SEI foram se formando pouco a pouco à medida que os alunos iam participando das "Atividade práticas", mas sobretudo nos diálogos estabelecidos com a pesquisadora acerca de seus conhecimentos e vivências sobre os temas desenvolvidos nas "Atividades Práticas". Com isso, os alunos se apropriaram de conceitos científicos e ressignificaram os saberes populares advindos de sua vivência ao longo de seus 65 anos de vida (em média). Na interrelação saberes populares, segundo o contexto do cotidiano, e saberes científicos, segundo o contexto da Ciência, a partir de situações que permitiram aos alunos comunicarem suas ideias em um ambiente de diálogo, voltado para os processos de aprendizagem, as rodas de conversa ficaram impregnadas desses novos saberes.

Por fim, acreditamos que a partir de "Atividade Prática" como essa, descrita na pesquisa, os alunos podem compreender os conteúdos específicos de ciências de forma mais integrada, relevante e contextualizada desenvolvendo habilidades necessárias ao fazer científico.

\section{Referências}

BEZERRA, D.B.; SANTOS, A.C. Ensino de Ciências na Educação de Jovens e Adultos: (Res)Significando Saberes na Produção de Fanzines. Revista de Educação, Ciências e Matemática, v. 6, n. 1, jan./abr., 2016.

CARVALHO, A.M.P. O ensino de Ciências e a proposição de sequências de ensino investigativas. p. 1-20. In: CARVALHO, A.M.P. (Org.). Ensino de Ciências por Investigação: condições para implementação em sala de aula. São Paulo: Cengage Learning, 2018.

KRASILCHIK, M. Prática de Ensino de Biologia. 4 ed. São Paulo: EdUSP, 2008.

LUNETTA, V. N. Actividades práticas no ensino da Ciência. Revista Portuguesa de Educação, v. 2, n. 1, p. 81-90, 1991

MINAYO, M. C. S. (org). Pesquisa social: teoria: método e criatividade. Petrópolis - Rio de Janeiro, Vozes, 1994. 
OLIVEIRA, M. K. Jovens e adultos como sujeitos de ensino e aprendizagem. Revista brasileira de Educação, n.12, p.59-73, set./out./nov./dez. 1999.

OLIVEIRA, C.M.A.; CARVALHO, A.M.P. Escrevendo em Aulas de Ciências. Ciência e Educação, v. It, p. 347-366, 2005.

ROCHA, D. As "Atividades práticas" para ensinar e aprender ciências em uma turma de educação de jovens, adultos e idosos. 121f. Dissertação (Mestrado Profissional em Formação Docente para a Educação Básica). Universidade de Uberaba. Uberlândia, 2019.

SANTOS, N.M.R.; SOTERO, A.E.S.; BENDITO, D.V.; OLIVEIRA, L.S.C. O Ensino de Ciências como Prática em Laboratório para Alunos da EJA. (2005). IV Congresso Nacional de Educação - CONEDU. Disponível em: www.conedu.com.br. Acesso em: 20, agosto de 2019.

SILVA, P. A. B.; LEITE, A. C. S., DELL' ARETTI, B. A., VELLASCO, D. G., VAZ, A. C. R. Construindo conceitos biológicos e históricos com os temas reprodução e sexualidade de maneira interdisciplinar. In: CONGRESSO BRASILEIRO DE EXTENSÃO UNIVERSITÁRIA, 2, 2004, Belo Horizonte. Anais... Belo Horizonte, 2004. Disponível em CD - ROM

SPERANDIO, M.R.C.; ROSSIERI, R.A.; ROCHA, Z.D.C.; GOYA, A. O ensino de Ciências por investigação no processo de alfabetização e letramento de alunos dos anos iniciais do ensino fundamental. Experiências em Ensino de Ciências, v. 12, no. 4, 2017. 